\title{
IFPR
}

\section{MECHANIZATION GROWTH AND DECLINING FARM SIZE IN SOUTH ASIA: \\ EXPLORING THE ROLE OF BIOLOGICAL TECHNOLOGIES IN NEPAL TERAI}

\section{HIROYUKI TAKESHIMA, YANYAN LIU}

T he agricultural sector in developing countries including those in South Asia, like Nepal, faces dual challenges of the persistent dominance of smallholder-based farming, and at the same time, rising labor costs due partly to growing non-farm sectors. The underlying factors that lead to the co-existence of these seemingly conflicting patterns are not yet clear. However, an important consequence is that inclusive agricultural transformation requires increased agricultural capital use like machines among these smallholders that remain in the agricultural sector. Studying the experiences in lowland Nepal (Terai zone) which has seen significant growth in tractor use since the mid-90s, despite the continuous decrease in average farm size, offers useful insights into what induce the adoptions of mechanization among smallholders who naturally lack the scope for exploiting the scale economies due to complementarity between machine and land.

We test the hypotheses that high-yielding technologies, which potentially raise returns to more intensive farm power use, are important drivers of adoptions of agricultural mechanization among smallholders. We do so by using two-rounds of Agricultural Census

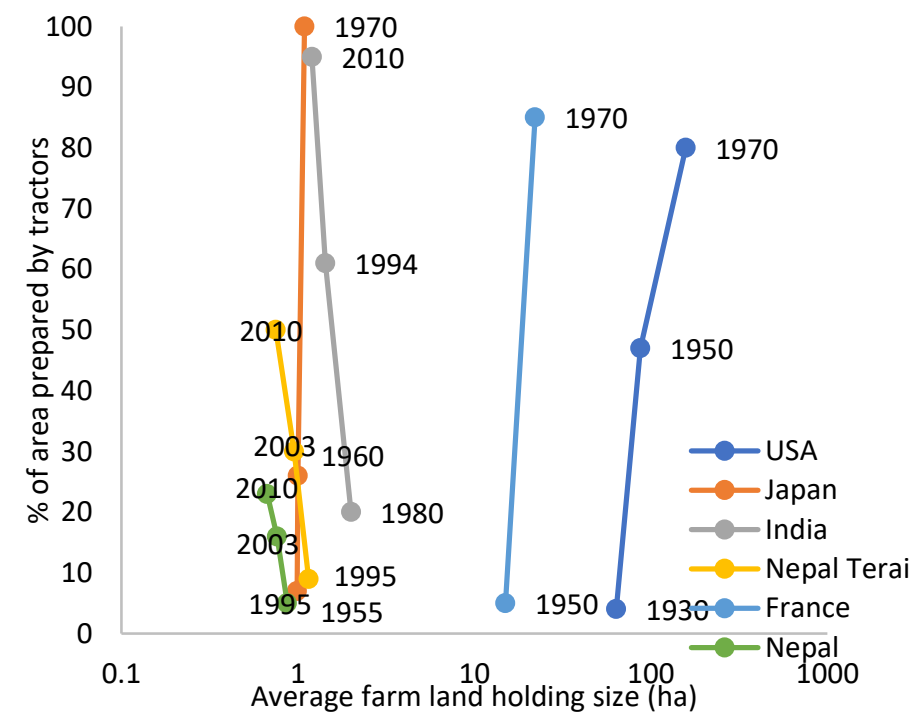

Figure 1. Mechanization growth among smallholders in South Asia Source: Takeshima \& Liu (2018). data in Nepal, as well as Nepal Living Standard Survey (NLSS), and indicators of agroclimatic similarity with plant-breeding locations within Nepal.

\section{GROWING TRACTOR USE WITHOUT FARM SIZE GROWTH}

While most countries have seen rising average farm size increase during periods of increased tractor use in South Asian countries like Nepal and India, a different trend has emerged. These countries have seen growth in tractor use occurring alongside declining average farm sizes (Error! Reference source not found.).

Figure 5 shows the relationship between tractor adoption rates and farm size in lowland Nepal in 2001 and 2011, respectively. Tractor adoptions are positively associated with farm size in both periods, which is consistent with the complementarity between machinery and land. However, we see considerable growth in tractor adoptions even among small farms (below 0.5 ha) from 2001 to 2011.

\section{Descriptive patterns indicating the linkage between high-yielding varieties and small- holder tractor adoptions}

In Nepal, the public sector has led plant breeding activities since the institutionalization of varietal development activities in the 1950s. Most improved varieties released have been tested on Agriculture Farms where the head offices of Commodity Research Programs or the Regional Agricultural Research Stations are located or on Agronomy Farms that belong to Universities. The locations of these farms (Figure 4) were mostly selected during the 1960s through the 1990s.

For the locations of each farm household in Nepal, Agroclimatic similarity with these plant-breeding locations (Figure 4) can be indexed by investigating agroclimatic conditions of each location, including rainfall, temperature, soil characteristics (drainage, sodicity, salinity, texture, organic carbon contents, acidity), hydrological conditions (distance to major rivers, groundwater depth), topography (ruggedness, slope) (Takeshima \& Liu 2018). 


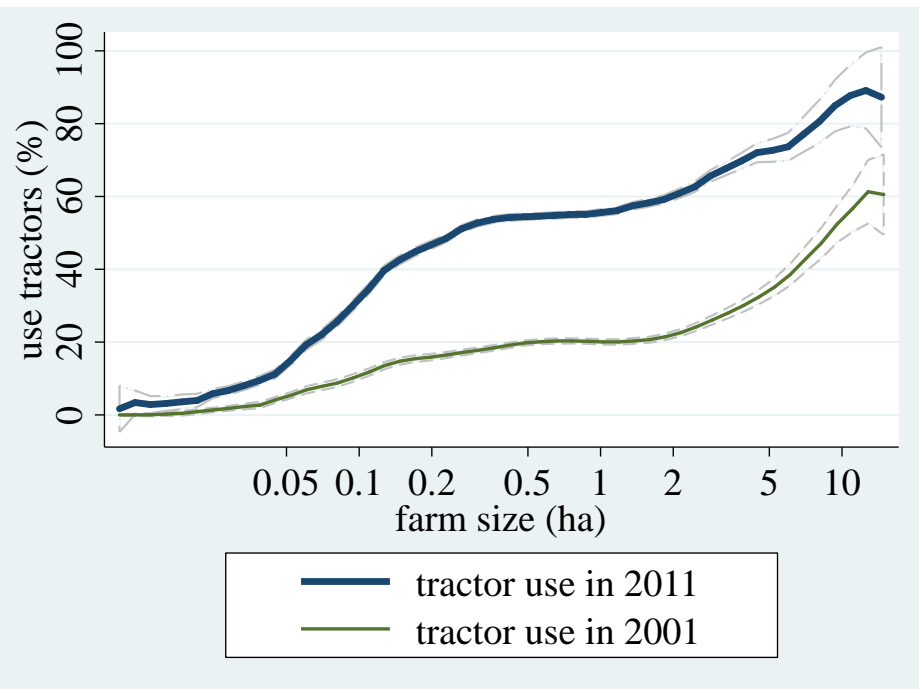

Figure 5.Growth of tractor adoption rates in Nepal Terai between 2001 and 2011, by farm size.

Source: Authors based on the Nepal Agricultural Census Data 2001 and 2011.

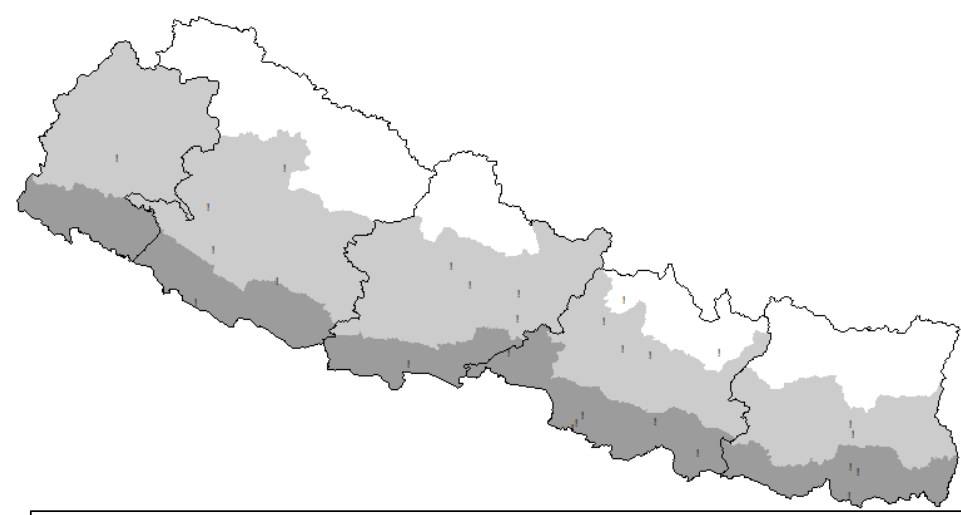

Figure 4.Three agroecological belts and five development regions in Nepal, as well as locations of Agriculture Research Stations and major universities with breeding activities

Source: Authors' compilations from various sources.

Note: Black dots indicate Agriculture Research Stations and key universities with plant-breeding activities.

Figure 3 illustrates the differences in the adoption curves between areas that share more, or less, similar agroclimatic environments with PBIs, separated at the median value of the agroclimatic similarity index in 2001 and 2011, respectively. Both periods indicate that tractor adoption rates are higher in areas with higher agroclimatic similarity, particularly among the smaller farms. The association between tractor adoption rates and farm size, which is positive even for small farms, is particularly strong in areas with high agroclimatic similarity. These patterns further motivate our analyses regarding whether higher agroclimatic similarity, which raises the productivity of improved varieties, also induces increased mechanization among smallholders.

Similarly, Figure 2 depicts the tractor adoption rate conditional on farm size for EAs with a higher area share of improved varieties (above the sample median) versus EAs with a low area share of improved varieties. Tractor adoption rates among smaller farms (less than 0.5 ha) are higher in EAs where more improved varieties are
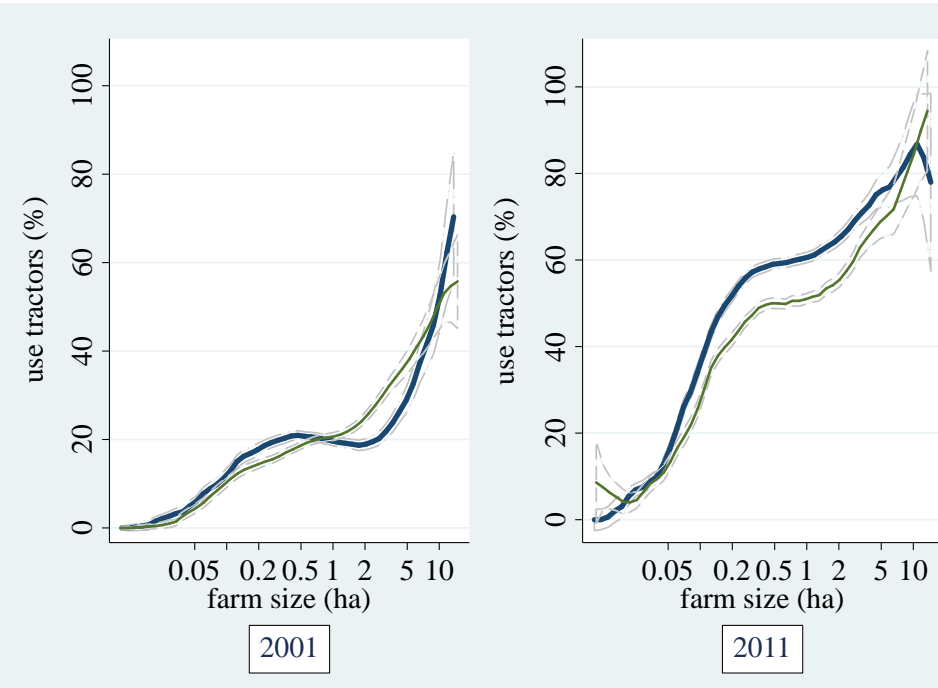

Figure 3.Tractor adoption rates, farm size, differentiated by Agroclimatic Similarity (Terai, 2001 and 2011).

Source: Authors based on the Nepal Agricultural Census Data 2001 and 2011.

Thick line $=$ High agroclimatic similarity area.

Thin line $=$ Low agroclimatic similarity area.
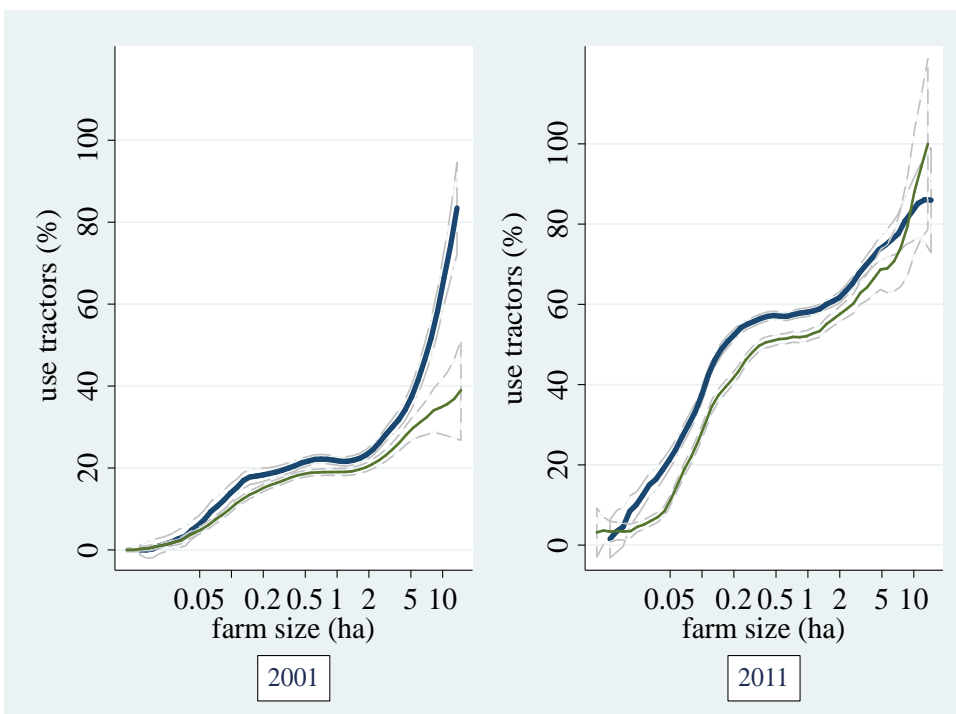

Figure 2.Tractor adoption rate and farm size, differentiated between enumeration areas with more / fewer households using improved varieties (Terai, 2001 and 2011).

Source: Authors based on the Nepal Agricultural Census Data 2001 and 2011.

Thick line $=$ More improved varieties

Thin line $=$ Less improved varieties

adopted, showing a positive association between improved varieties and tractor adoption among smaller farms. This pattern appears particularly clear among smaller farms and less significant among larger farms.

AGROCLIMATIC SIMILARITY WITH PLANT BREEDING LOCATIONS AND TRACTOR ADOPTIONS 
Table 1 presents the estimation results from equation (4) using Census 2001-2002 data for households with land holdings under 0.1 ha (columns 1-3), under 0.5 ha (columns $4-6)$, under 1.0 ha (columns 7-9), above 1.0 ha (columns 10-12), and above 2.0 ha (columns 1315), respectively.

Consistent with our hypothesis, agroclimatic similarity has statistically significant, positive effects on tractor adoption among farmers with less than 1 ha of farmland. The effects of agroclimatic similarity are weaker for farm households with more than 1 ha of land. On average, an increase in agroclimatic similarity by one stand- regular level but the magnitude is small ( -0.2 percentage points for the former group and 0.1 percentage points for the latter group). This result is consistent with our hypothesis that larger farms have already experienced high rates of machinery adoption because of the complementarity between machinery and land holdings; thus their adoption is less affected by improved varieties than smaller farms.

\section{Adoptions of improved varieties and tractor adoptions by smallholders}

Table 2 reports the effects of the adoption of improved varieties

Table 1. Effects of agroclimatic similarity on tractor adoption decisions, differentiated by land holding size, in Nepal Terai in 2001a,b

Dependent variable $=$ trac -

tor adoptions (yes $=1$ )

$<0.1$ ha

Samples by land-holding size

\begin{tabular}{|c|c|c|c|c|c|c|c|c|c|c|c|c|c|c|c|}
\hline & $(1)$ & $(2)$ & (3) & (4) & (5) & (6) & (7) & (8) & (9) & $(10)$ & $(11)$ & (12) & (13) & (14) & (15) \\
\hline \multirow[t]{2}{*}{ Agroclimatic similarity } & $017^{* *}$ & $.017^{* *}$ & & $.030 * *$ & & & $.028 * *$ & & & $.007^{\dagger}$ & $.007^{*}$ & -.002 & -.004 & -.004 & .001 \\
\hline & $(.003)$ & $(.003)$ & $(.007)$ & $(.002)$ & $(.002)$ & $(.005)$ & $(.002)$ & $(.002)$ & $(.005)$ & $(.004)$ & $(.004)$ & $(.008)$ & $(.007)$ & (.007) & $(.016)$ \\
\hline \multirow{4}{*}{$\begin{array}{l}\text { Agroclimatic similarity } \times \text { In } \\
\text { (farm size) } \\
\text { In (farm size) }\end{array}$} & 020 & .019 & .01 & $.006^{*}$ & $.005^{*}$ & & .000 & .0 & & & & & $.033^{+}$ & .028 & $.031^{\dagger}$ \\
\hline & 10 & $(.006)$ & $(.006)$ & $(.002)$ & $(.00$ & 1.0 & $(.002)$ & $(.0$ & l. & $(.0$ & $(.0$ & & 8) & $(.0$ & $(.017)$ \\
\hline & .034 & .033 & .02 & .050 & $.04 \varepsilon$ & .04 & $.045^{* *}$ & .04 & .04 & .09 & .08 & .0 & $* *$ & .13 & $.137 * *$ \\
\hline & & $(.0$ & & $(.0$ & 1.0 & & $(.002)$ & $(.0$ & & $(.009)$ & & & & & \\
\hline \multirow[t]{2}{*}{ Distance to $\mathrm{PBI}$} & -.002 & -.003 & $-.027 * *$ & $-.019 * *$ & $-.018^{* *}$ & -.0 & $-.020 * *$ & $-.020^{*}$ & & $-.031 * *$ & -.03 & & -.04 & -.0 & -.0 \\
\hline & $(.0$ & $(.004)$ & & $(.0$ & $(.0$ & & $(.0$ & & & & & & & & \\
\hline \multirow{2}{*}{$\begin{array}{l}\text { Distance to } \mathrm{PBI} \times \ln (\text { farm } \\
\text { size) }\end{array}$} & .0 & .003 & & $-.005^{+}$ & & & $-.007^{* *}$ & $-.006 *$ & & -.0 & & & & & \\
\hline & $(.00$ & 1.00 & & $(.0$ & & & $(.003)$ & & & & & & & & \\
\hline Other socioeconomic varia & Yes & Yes & Yes & Yes & Yes & $y$ & Yes & Yes & $Y$ & Yes & $\mathrm{Y}$ & 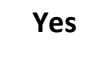 & $\mathrm{Ye}$ & 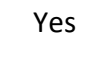 & s \\
\hline Oth & & Yes & Yes & & 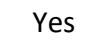 & Ye & & Yes & $Y \epsilon$ & & Ye & & & . & \\
\hline & & & & & & Yes & & & Yes & & & & & & Yes \\
\hline Number of observations & 4,236 & 4,236 & 4,236 & 17,237 & 17,237 & 17,237 & 26,093 &, 093 & 26,093 & 12,226 & 12,226 & 12,226 & 4,570 & 4,570 & 4,570 \\
\hline
\end{tabular}

Source: Authors' estimations based on the census data.

Asterisks indicate the statistical significance: ${ }^{* *} 1 \%, * 5 \%,+10 \%$

aBoth agroclimatic similarity and In (land holding size) are demeaned within the corresponding samples. Therefore, coefficients for non-interacted variables are average partial effects for all corresponding samples.

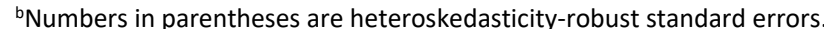

Table 2. Effects of the adoptions of improved varieties on tractor adoption decisions, differentiated by land holding size, in Nepal Terai in $2001^{a}$

Dependent variable $=$ tractor

adoptions (yes $=1$ )

$<0.1$ ha

Samples by land-holding size

(8) (9)

(10)

(11)

Area share of improved varie- $1.397^{*} 1.488^{*} 1.809^{\dagger} 2.039 * 2.284^{\dagger} \mathbf{2 . 1 8 9 ^ { \dagger }} 1.661 * * 1.815^{* *} 1.733 * \quad .125$

ties

$\begin{array}{lllllllllllllllll}. .679) & (.745) & (.961) & (1.026)(1.238)(1.129) & (.712) & (.839) & (.762) & (.234) & (.250) & (.239) & (.507) & (.592) & (.552)\end{array}$

Other socioeconomic varia- Yes Yes Yes Yes Yes Yes Yes Yes Yes Yes Yes Yes Yes Yes Yes

bles and intercept

Other asset

plot soil variables

Yes Yes

Yes

Yes Yes

Yes Yes

Yes

\section{Yes}

Yes

\begin{tabular}{|c|c|c|c|c|c|c|c|c|c|c|c|c|c|c|c|}
\hline plot & & & Yes & & & Yes & & & Yes & & & Yes & & & Yes \\
\hline Number of observations & 4,236 & 4,236 & 4,236 & 17,237 & 17,237 & 17,237 & 26,093 & 26,093 & 26,093 & 12,226 & 12,226 & 12,226 & 4,570 & 4,570 & 4,570 \\
\hline $\mathrm{p}$-value (HO: overidentified) & .242 & .291 & .562 & .771 & .858 & .710 & .741 & .534 & .108 & .605 & .398 & .305 & .383 & .289 & .301 \\
\hline p-value (HO: exogeneity) & .000 & .000 & .000 & .000 & .000 & .000 & .000 & .000 & .000 & .669 & 692 & .720 & 134 & 124 & 108 \\
\hline
\end{tabular}

Source: Authors' estimations based on the census data.

Asterisks indicate the statistical significance: $* * 1 \%, * 5 \%,+10 \%$

a Numbers in parentheses are EA cluster-adjusted standard errors.

ard deviation increases the probability of tractor adoption by 1.5 percentage points for the under- 0.1 ha group, by 1.3 percentage points for the under- 0.5 ha group, and by 1.0 percentage points for the under-1 ha group. These effects translate into an increase in tractor adoption of 36 percent for the under- 0.1 ha group, 10 percent for the under-0.5 ha group, and 6 percent for the under- 1 ha group.

In contrast, for the above- 1 ha group and the above- 2 ha group, the effect of agroclimatic similarity is statistically insignificant at any on tractor adoption using Census 2001 data for the five sub-groups. Consistent with our findings from Table 1, the share of areas using improved varieties has a significantly positive effect among farm households with less than 1 ha of land but has an insignificant and relatively small effect among larger farms. One percentage point increase in the share of areas using improved varieties increases the probability of tractor adoption by $1.8,2.2$, and 1.7 percentage points for the under-0.1 ha, the under-0.5 ha, and the under-1 ha group, respectively. 
We also conduct robustness checks by estimating the same model using the Census 2011 data which only reports household locations at district level rather than lower administrative levels, and identify the variations in agroclimatic similarity only at the district level (Table 3). Our findings in Table 1 still largely hold in 2011, by which time the overall tractor adoption rates had risen considerably. Robustness of results based on Nepal Living

Table 3. Effects of agroclimatic similarity on tractor adoption decisions, differentiated by land holding size, in Nepal Terai in 2011 a, b Dependent variable $=\quad$ Samples by land-holding size (ha)

\begin{tabular}{llllll}
\cline { 2 - 6 } tractor adoptions (yes = 1) & $<0.1<0.5$ & $<1.0$ & $>1.0$ & $>2.0$ \\
\hline Agroclimatic similarity & $136 * *$ & $152 * *$ & $140 * *$ & $.065 * *$ & $052 * *$
\end{tabular}

\begin{tabular}{lcccccc}
\hline Agroclimatic similarity & $.136^{* *}$ & $.152^{* *}$ & $.140^{* *}$ & $.065^{* *}$ & $.052^{* *}$ \\
& $(.010)$ & $(.006)$ & $(.005)$ & $(.007)$ & $(.011)$
\end{tabular}

$\begin{array}{lllllll}\text { Agroclimatic similarity } \times \ln & .066^{* *} & .008 & .002 & -.018 & -.072 *\end{array}$

$\begin{array}{llllll}(\text { farm size) } \quad(.017) & (.005) & (.004) & (.014) & (.031)\end{array}$

$\begin{array}{lllllll}\text { In (farm size) } & .148^{* *} & .179 * * & .142 * * & .090^{* *} & .078^{* *} \\ & (.010) & (.003) & (.002) & (.012) & (.024)\end{array}$

Other controls $\quad$ Yes Yes Yes Yes Yes

\begin{tabular}{llllll}
\hline Number of observations & 5,137 & 21,270 & 31,371 & 10,677 & 3,429
\end{tabular}

Source: Authors' estimations based on the census data.

Asterisks indicate the statistical significance: $* * 1 \%, * 5 \%,+10 \%$

aboth agroclimatic similarity and In (land holding size) are demeaned within the corresponding samples. Therefore, coefficients for non-interacted variables are average partial effects for all corresponding samples.

${ }^{b}$ Numbers in parentheses are heteroskedasticity-robust standard errors.

\section{Standard Survey}

Supplemental results based on NLSS further suggest that the results from the Census data are robust and are also consistent with the conceptual framework of the potential linkages between improved varieties and returns to tractors and their differences between smallholders and large farms.

Table 4 shows that the effects of the adoption of improved varieties on tractor adoption are more positive and statistically significant among smaller farms. Furthermore, the estimated magnitudes are also similar to those in Table 2.

Table 5 shows the effects of tractor adoption on agricultural incomes, as well as those effects' variations across farm size and agroclimatic similarity, estimated by stratified propensity score matching method. The results show that among smaller farms, the effects of tractor adoption have more positive associations with agricultural incomes in areas with higher agroclimatic similarity. These relationships do not hold true among larger farms. This is consistent with our conceptual framework: higher TFP induced by higher agroclimatic similarity and greater availability of improved varieties raises returns to tractor adoption, and these are the primary sources of returns to tractor adoption for smallholders with less scope to exploit tractor's complementarity with land.

Table 4. Effects of the adoptions of improved varieties on tractor adoption decisions, differentiated by land holding size (NLSS data)

Dependent variable $=$ tractor

doptions (yes $=1$ )

Are

Area share of improved varie-

ies

Other controls

Other asset

Number of observations ${ }^{b}$

p-value (HO: overidentified)

p-value (HO: exogeneity)

Source: Authors' estimations based on the NLSS data.

Asterisks indicate the statistical significance: ** $1 \%, * 5 \%,+10 \%$

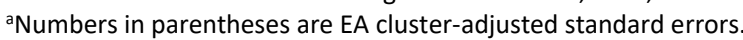

${ }^{\mathrm{b} S}$ Samples not reporting the type of varieties are excluded.

Table 5. Associations between the adoptions of tractors and agricul-

tural incomes, differentiated by land holding size and agroclimatic sim-

ilarity (NLSS data)

\begin{tabular}{|c|c|c|c|}
\hline \multirow[t]{2}{*}{ Categories } & & \multicolumn{2}{|c|}{ Agroclimatic similarity } \\
\hline & & above median & below median \\
\hline \multirow{2}{*}{$\begin{array}{l}\text { Small farms } \\
\text { (owning less } \\
\text { than } 0.5 \text { ha) }\end{array}$} & $\begin{array}{l}\text { \% increase in agri- } \\
\text { cultural incomes }\end{array}$ & $.308 * * *(.107)$ & $.131(.108)$ \\
\hline & $\begin{array}{l}\text { Sample size (on- } \\
\text { support) }\end{array}$ & 733 & 819 \\
\hline \multirow{2}{*}{$\begin{array}{l}\text { Large farms } \\
\text { (owning at } \\
\text { least } 0.5 \mathrm{ha} \text { ) }\end{array}$} & $\begin{array}{l}\text { \% increase in agri- } \\
\text { cultural incomes }\end{array}$ & $.104(.082)$ & $.004(.085)$ \\
\hline & $\begin{array}{l}\text { Sample size (on- } \\
\text { support) }\end{array}$ & 861 & 779 \\
\hline
\end{tabular}

\section{POLICY RECOMMENDATIONS}

Demand for mechanization generally rises when the agricultural sector increasingly faces labor scarcity or rising labor costs due to labor movement into the non-farm sector, including farm household family members. However, this process is much slower at the farm household level, leading to dual-challenges where a large number of smallholders remain in the agricultural sector while, at the same time, facing labor scarcity. Smallholders also face constraints in leaving the agricultural sector, due to the lack of capital, or food security concern due to food market risks. Therefore, supporting smallholders remain important even in the face of growing labor scarcity. Such support includes improving access to agricultural machinery like tractors.

Despite the conventional wisdom that tractor is only for largescale farming, experiences in lowland Nepal show that tractor has been demanded and adopted by smallholders, though the adoption rate remains relatively low.

To increase machinery adoptions among smallholders (particularly those owning less than 1 ha of farmland), many constraints need to be removed, including technological and institutional factors. To remove technological constraints, government's support of the diffusion of high-yielding varieties is highly desirable. One way to do so may be to expand the plant-breeding locations, especially in areas that are distinct from existing plant-breeding locations in terms of agroclimatic conditions. Doing so will particularly raise demand for tractors among smallholders located in areas that share similar agroclimatic conditions with those new plant-breeding 
locations, for which current yield potential is low, and demand is insignificant.

Custom hiring tractor service brings mechanization to smallholders, but their sparsity still constrains the adoptions. Our findings support that increasing the intensity of demand for tractors is critical for inducing custom-hiring service providers to serve smallholders, which incurs higher transactions costs. Providing high-yielding technologies is one effective way to induce such demand increase.

Importantly, however, this approach is less effective for relatively larger smallholders (owning more than 1 ha of farmland), who adopt tractors more because they can reap enough benefits exploiting scale economy.

We gratefully acknowledge funding support from Syngenta Foundation for Sustainable Agriculture and the CGIAR Research Program on Policies, Institutions, and Markets (PIM).

\section{INTERNATIONAL FOOD POLICY RESEARCH INSTITUTE \\ A member of the CGIAR Consortium | A world free of hunger and malnutrition \\ 1201 I Street, NW | Washington, DC 20005 USA \\ $\mathrm{T}:+1.202 .862 .5600 \mid \mathrm{F}:+1.202 .467 .4439$ \\ Email: ifpri@cgiar.org |www.ifpri.org}

This publication has been prepared as an output from the project - mechanization process in Asia and its implication in SSA. It has not been peer reviewed. Any opinions stated herein are those of the author(s) and are not necessarily

representative of or endorsed by the International Food Policy Research Institute.

Copyright @ 2019 International Food Policy Research Institute. All rights reserved. To obtain permission to repub-

lish, contact ifpri-copyright@cgiar.org. 